\title{
Initiation into street, challenges, means of survival and perceived strategies to alleviate its plights among street children in Addis Ababa, Ethiopia 2019 A phenomenological study design
}

Ayana Fite Chimdessa ( $\nabla$ ayanayoom@gmail.com )

Research article

Keywords: street children, Ethiopia, Time-Space Sampling, Policy

Posted Date: June 23rd, 2020

DOI: https://doi.org/10.21203/rs.2.22484/v3

License: (a) This work is licensed under a Creative Commons Attribution 4.0 International License. Read Full License 


\section{Abstract}

Background: There has been a major discrepancy in defining the term street children-where various stakeholders define in different ways. In spite of increasing in number, the life and health of street children is becoming a global concern. Even though a wide range of policies and strategies are available, they are poorly designed with helpless implementation. This made street children defenseless to harassments and denial of social protection services.

Methods: A phenomenological study design was employed to explore difficulties of the street children and perceived strategies to prevent and alleviate plights. The study was conducted from January to March 2019. A Time-Space Sampling (TSS) was used to recruit participants. Pre-tested interview guide was used for data collection. Data was analyzed by using framework analysis software.

Results: A total of 103 street children took part in the study. Complexity of push and pull factors pose to risk of flee into the street. Street children are facing widespread challenges i.e. social network fragmentation, child trafficking, harassments and shortage of coverage of basic needs. Furthermore, absences of comprehensive and contextualized strategies and less political value for this group worsening it. Thus, street children have been considered as felon, out laws and having a mentality of committing crime by both law keeping bodies and society. This in turn, affecting street children's' acceptance by their community and get legal protection under the law and made them more risk to denial of social protection services. To win street life struggles, they use different survival mechanisms by forming small group. Income Generating Activities (IGAs), shelter, community support, child protection, access to health education, health services, life coaching and by less extent reintegration are positively perceived strategies to address their problems.

Conclusion: Lack/poorly designed policies and strategies targeting street children has made them prone to health and social problems. Furthermore, stigma by community, limited resources, lack of comprehensive standards and absence of political value of interventions exacerbating it. Therefore, call for different stakeholders in supporting to design and implement clear, case based and contextualized strategic policies to address and prevent plights; by considering positively perceived street children's strategies.

\section{Background}

There has been a major inconsistency in defining the term "street children". All legal constitution, non-governmental organizations, researchers and media, define the term street children in different ways [1]. The legal social defense department and various legislators consider street children as children exposed to delinquency [1]. However, United Nations Children's Fund has labeled them as children in difficult circumstances, which represent a minority population that have been under-represented for too long in health research [2]. Children who live in the streets are difficult to define, since they are not homogenous groups, and the way they use the streets varies widely and challenging to arrive at watertight definitions [3]. The use of terms that label and stigmatize children should be avoided as much as possible in order to preserve their dignity and generate improved public as-well-as official's attitude towards them $[2,3]$. They are at risk of carrying a greater disease burden. Further research on the health risks and health status of street children is also required, particularly in Sub- Saharan Africa, which carries the greatest disease burden [2,3].

Though they are hard to count, the number of street children is increasing for various reasons [4]. Recent global estimate showed that nearly 150 million street children are living in the urban and semi-urban areas [4,5]. Evidences show that both pushing and pulling factors are influencing, motivating and drawing children to leave/escape from home and flee into the street. Factors related to family loss due to HIV/AIDS, land grab and family eviction, family disruption; social marginalization, poverty, peer influence and desire to live in cities etc. have been strongly associated reasons [4,5].

In spite of increasing in number, the life and health of street children is becoming a global concern. Children who spend time in the street are at risk of health and social problems, bizarre behaviors i.e. aggression, hopelessness with high prevalence of drug use [6]. The systematic review of Low and Middle Income Countries (LMICs) illustrates that youth's survival behaviors and exposures associated with poor shelter and survival mechanisms have resulted in disproportionate morbidity in the area of infectious diseases, psychiatry, reproductive health and by lesser extent growth [7]. Furthermore, other evidences in LMICs show that street youth experience hopelessness, depressive symptoms, self-harm and suicidal attempt. Suicide attempts are reported across studies by $2 \%$ to $23 \%$ of street children [8]. The study used DSM-TR criteria to diagnose Post-Traumatic Symptom Disorder (PTSD) shows that about $69.3 \%$ of street youth (male- $72.1 \%$ and female- $56.1 \%$ ) are diagnosed with schizophrenia (SZ) and $30.7 \%$ are diagnosed with Bi-polar Disorder (BD) [9]. Similarly, the study shows that about $59 \%$ of street female are diagnosed with major depressive episodes and $25.7 \%$ of street male and $16.4 \%$ of female are at risk of self-suicide intention [10]. Concurrently, in Ethiopia evidences show that street children are facing many difficulties of health and social problems. Three years back, I studied sexual and physical abuse and its determinants as-well- as vulnerability of street children towards HIV and Sexually Transmitted Infections (STIs) in Ethiopia. The finding show that street children are high risk of sexual and physical exploitations as-well- as about 2.5 times more likely vulnerable to HIV and STIs [11]. More than 869, 567 (age 10 to 14 years) children illegally migrated to abroad (particularly to Saudi), $70 \%$ girls are sexually abused and $30 \%$ girls raped before reaching the age of eighteen. Below 15 years, $48.6 \%$ of children engaged in child labor [12]. 
Alongside, lack of shelter imposing both male and female to have the same sleeping quarter, turning to prostitution for survival-which, mark rampant sexual harassment among themselves and outsiders [13]. Where, about $46.4 \%$ of street children have practiced sexual intercourse before reaching the age of sixteen, of which, $32.2 \%$ forcefully raped, $17.4 \%$ started to drive for social connection [14]. However, condom use practice is very poor (14.3\%)where, partner refusal (44.8\%), unplanned sex (41.7\%), too young to negotiate (39.6\%) are being the reasons. About $75 \%$ and $85.7 \%$ of street children have had multiple sexual partners and practiced survival sex, respectively [15]. All these practices are hitting them under high burden of disease and its psychological impacts $[11,15]$. The study conducted in southern Ethiopia shows that $13.8 \%$ experienced bad-smelling genital discharge, genital ulcers (11.2\%), and burning sensation (14.5\%) during urination. However, only $15.3 \%$ of them received treatment from healthcare providers [16]. Poor mental health is another major challenge. Street children in Ethiopia reported that they feel hopelessness, lonely, and social isolation, which place them under mood depression [11].

Programmes in LMICs should be place clear, contextualized and case based analysis to address predicaments of street children [2]. Programmes and policy frameworks should use recent evidences and most realistic estimates of street children, since the phenomenon of street life varies with contexts, time and become more complex. This pose challenges for organizations to design and implement programmes effectively and efficiently. Thus, reason to flee into the street and experiences of life difficulties by sub-group are crucial to respond by broad coalitions of concerned stakeholders, effectively and efficiently $[2,17]$. To develop clear, comprehensive and contextualizing strategies, understanding of their experiences, reason to flee and relationships are pivotal to recommend politicians and policy makers for effective programing. Commitment of politicians and political value of such intervention programmes are in need of attention to improve their right, health and wellbeing.

Despite to these facts, studies indicate that problems of street children have been ignored by government and general public, causing a devastating impact on the development of African nations. Government policies that promote liberalization and free market economy are becoming factors contributing to persistent state of poverty, leaving children to be most affected. As a result, families are becoming major cause of problems and schools are becoming centers of violence and crime pertaining and increasing numbers of street children [17]. Furthermore, in Africa, poor program design, helpless implementation of policies and strategies and absence of political value of such interventions exacerbating the problems. There is a wide range of legislation relevant to street children. However, they are seldom specifically mentioned, and their rights and issues are not specifically addressed [2,3]. The traditional response to street children by most governments in Africa and elsewhere has been repression-where they do not offer any viable alternative. Politicians, policy makers, and urban planners seem to be helpless in their efforts to either resolve the problems or assist street children, and to date, failed to prescribe realistic and concrete solutions. It appears that African governments pay lip-service to the idea of improving care for street children [17].

Concomitantly, Ethiopian government is not exceptional- where street children are suffering from similar challenges too. The government is seeming helpless in setting comprehensive, contextualized and case based strategies to address and prevent their problems. On my previous articles, I recommended both government and non-government organizations to consider and set in place programmes like violence reduction, re-integration, IGAs and social protection systems [11,14]. In view of this, after three years, the researcher aimed to obtain deeper insights of street children's life status, life difficulties, so far actions taken by both government and non-governmental organizations and what strategies street children perceive and propose, that have to be considered by the acting bodies, to address and prevent plights against them. I hope, insights from this study will inform policy makers and urban planners to set comprehensive, contextualized and case based programs and integrated social protection frameworks in place to revitalize efforts to support this victimized group of young people in Ethiopia.

\section{Methods}

\section{Study design}

A Phenomenological qualitative approach was underpinned to explore the deeper insights of street children's experiences of initiation into the street, challenges, means of survival and perceived strategies to alleviate street life difficulties.

\section{Sample size}

A Time-Space-Sampling (TSS) strategy was used to recruit participants into the study, since study populations are hard-to-reach population. First, locations were selected randomly from the sampling frame and their average number during fixed time was considered-where, participants recruited by equal probability from each cluster during equal time periods. All street children age ranged from 10 to 18 years were eligible. The initial plan was to conduct 15 in-depth interviews and 5 FGDs. However, recruitment continued until data saturation was reached. Where, information saturation was determined by redundancy of response, adding more participants into the study did not result in obtaining additional perspectives of required 
information, sub-group homogeneity of lived experiences, qualitative data collectors' expertise considered. Thus, a total of 26 in-depth interviews and 7 FGDs conducted (refer Table 1).

\section{Data Collection}

The study used a pre-tested interview guide to ensure that questions were unambiguous or not for gathering information. Pre-test conducted on $10 \%$ of the initial plan and based on the result, some questions were adjusted into the easy way for understanding. Two supervisors and six certified assessors of middle health professionals recruited for data collection, where all of them attended a two-day training program in Addis Ababa, Ethiopia. The training focused on the purpose of the study, ethical principles, sampling, interview techniques, how to take field note and audio recording. Data collection conducted from January to March 2019. Before conducting interview, data collectors explained the purpose of the study, and all participants assured that their information would be kept confidential. Data collectors obtained written assent and consent from study participants and guardians city mayor and/ or non-governmental organizations i.e. hope enterprise. All in-depth interviews and FGDs conducted in Amharic in private place for the purpose of concentration and privacy. FGD participants categorized into two based on their biological sex; let them disclose their physical and sexual experiences in detail and freely, since these are sensitive issues. Study subjects who have participated in FGD excluded from in-depth interview to allow let interviewees come with additional information and respond to required information in other perspective ways, if they have more information to the aim of the study. Data collection lasted for an average of 40-60 minutes. Interviews conducted by using tape recorder up to the level of information saturation. Data quality maintained by field supervisors through wrapped up of recorded data to ensure its completeness and clarity.

\section{Data processing and analysis}

The field note memos and audio-taped record were transcribed into Amharic and translated into English using a verbatim transcription. The translated data re-checked by the researcher by listening to audio tape records. Transcribed interviews imported into framework analysis software for analysis. Data analyses conducted in three stages: In the first stage, an analysis of framework was developed and the code book organized under three broad themes (initiation into street life, means of survival and perceived strategies to alleviate its challenges), sub-themes and categories were added after reviewing participants' responses (refer Table 2). In the second stage, coding was conducted by the researchers through an iteration process and many more elements related to study objectives added to framework analysis. In the third stage, final themes named and defined. Finally, results written by summarizing, interpreting and quoting, when needed.

\section{Ethics approval and consent to participate}

Ethical clearance was received from Ethiopian Public Health Institute (EPHI) review board. Further permissions were obtained from guardians or nongovernmental organizations (NGOs) that are working with street children. Since, the study participants were younger, written assent was taken from study subjects. To compensate participants' time, the researchers provided 50 ETB (1.9 USD) per person. Participation in the study was voluntary and information collected from the study subjects was handled confidentiality.

\section{Results}

\section{Demographic characteristics of study participants}

As shown in Table 1, a total of 103 ( $n=65$ male and $n=38$ female) of street children (age 10-18 years) took part in the study, where 26 ( $n=15$ male and $\mathrm{n}=11 \mathrm{female}$ ) are interviewed and 77 ( $\mathrm{n}=50$ male and $\mathrm{n}=27$ female) participated in (FGDs). Of the 103 participants, 38 never have been into schooling and 60 (58\%) of participants dropped their education; whereas, 5 (5\%) were into schooling by in and off style. About 40 (39\%) of participants informally "married" to one another to cope with the challenges of street life. Thirty-three participants newly joined into the street society, while 16 participants lived for more than 5 years (refer Table 1).

Table: 1, Demographic characteristic of street children in Addis Ababa, Ethiopia 2019. 


\begin{tabular}{|c|c|c|c|c|c|c|c|c|c|c|c|c|c|c|c|}
\hline \multirow{2}{*}{$\begin{array}{l}\text { Used } \\
\text { research } \\
\text { tools } \\
\text { FGDs }\end{array}$} & \multirow[t]{2}{*}{$\frac{\text { No of }}{\text { participants }}$} & \multicolumn{2}{|l|}{ Sex } & \multicolumn{4}{|c|}{ Educational background } & \multicolumn{4}{|c|}{ Years lived on-street } & \multicolumn{2}{|c|}{$\begin{array}{l}\text { Schooling } \\
\text { Status }\end{array}$} & \multicolumn{2}{|c|}{ Marital status } \\
\hline & & Male & Female & \multicolumn{2}{|c|}{$\begin{array}{l}\text { never } \\
\text { have been } \\
\text { into } \\
\text { school }\end{array}$} & $\begin{array}{l}\text { Primary } \\
(1 \text { to } 6)\end{array}$ & $\begin{array}{l}\text { Junior } \\
\text { 2ry } \\
\text { education } \\
(7 \& 8)\end{array}$ & $\begin{array}{l}\text { Newly } \\
\text { joined }\end{array}$ & $\begin{array}{l}\text { One } \\
\text { year }\end{array}$ & $\begin{array}{l}2- \\
5 \\
\text { yrs }\end{array}$ & $\begin{array}{l}5+ \\
\text { yrs }\end{array}$ & In & drop & Single & $\begin{array}{l}\text { Informally } \\
\text { married }\end{array}$ \\
\hline \multicolumn{16}{|c|}{ Male FGDs } \\
\hline FGD1 & 9 & 9 & - & 4 & 3 & & 2 & 5 & 2 & 1 & 1 & - & 9 & 5 & 4 \\
\hline FGD2 & 11 & 11 & - & 6 & 4 & & 1 & 4 & 5 & 2 & - & 1 & 10 & 7 & 4 \\
\hline FGD3 & 8 & 8 & - & 3 & 5 & & - & 2 & 3 & 3 & - & - & 8 & 6 & 2 \\
\hline FGD4 & 12 & 12 & - & 5 & 6 & & 1 & 3 & 6 & 1 & 2 & 1 & 11 & 7 & 5 \\
\hline FGD5 & 10 & 10 & - & 4 & 5 & & 1 & 3 & 4 & 2 & 1 & - & 10 & 6 & 4 \\
\hline \multicolumn{16}{|c|}{ Female FGDs } \\
\hline FGD6 & 8 & - & 8 & 5 & - & & 4 & 3 & 2 & 2 & 1 & - & 8 & 5 & 3 \\
\hline FGD7 & 10 & - & 10 & 6 & - & & 2 & 4 & 4 & 1 & 1 & - & 10 & 6 & 4 \\
\hline FGD8 & 9 & - & 9 & 6 & - & & 3 & 3 & 2 & 1 & 3 & 1 & 8 & 6 & 3 \\
\hline Total & 77 & 50 & 27 & 39 & 5 & & 24 & 27 & 28 & 13 & 9 & - & 74 & 48 & 29 \\
\hline \multicolumn{16}{|c|}{ In-depth interviews } \\
\hline & 26 & 15 & 11 & 15 & 9 & & 2 & 6 & 5 & 8 & 7 & 2 & 24 & 15 & 11 \\
\hline Total & 103 & 65 & 38 & 54 & 14 & & 26 & 33 & 33 & 21 & 16 & 5 & 98 & 63 & 40 \\
\hline
\end{tabular}

FGD $n=77$ ( $n=50$ males and $n=27$ females), In-depth interviews $n=26$ ( $n=15$ males and $n=11$ females).

The framework analysis findings of both in-depth interviews and FGDs of street children are presented in the table below.

Table: 2, Major thematic areas, sub- themes and categories of in-depth interviews and FGDs of street children in Ethiopia, 2019. 
Theme 1: Initiation into street life

1.1. Pushing/pulling factors into the street

1.2. Challenges of living in the street

1.2.1 Lack of social ties and networks

1.2.2 Critical shortage of coverage of basic needs

1.2.3 Physical, sexual and verbal harassments

1.2.4 Child trafficking

2.1. Formation of group life versus collective security

2.1.1. Inter or intra group conflict of interest

2.2 Sharing available resources and vital information

2.2.1 Sex as a means of survival

Theme 3: Available government structures and street children perceived strategies to alleviate and prevent the occurrence of plights.
3.1. Governmental and non-governmental structure to regulate and protect street children

3.2. Street children proposed perceived strategies to alleviate and prevent the occurrence of plights.

\subsubsection{Separate shelter to spend over the night}

3.2.2. Regular health education, health services and life coaching

3.2.3. Effective implementation of child protection policy

3.2.4. Creation of income generating activities for self-help

3.2.5. Community strengthening as a preventive strategy

3.2.6. Reintegration with families or extended relatives

Theme 1: Initiation into street life

Initiation into the street is a rite of passage marking entrance and acceptance into a society of street and participating its culture and work to survive. It might be either joining alone or as group into the street society due to variety of push/pull factors. When one joins, he/she will be introduced to the hierarchy of sub-group structure, line of command, power, sex, loyalty, role and responsibilities of the group members, since it is the beginning of new life. Five of the 7, (71.5\%) of discussants reported group joining has a great advantage than joining as single person into the street society. When you join by group, you do not have the problems of socialization with other street societies. You might not face the harassment of first day arrival by other groups or individuals. "Especially, if you have one or more experienced street child in the group, you will get the information how to live in the street, how to search for basic needs and security issues in the street. Such grouping is great that can survive and protect group members from any type of harassments" (FGD).

Participants reported "If you joined street society as a single person, your fate is on the hand of strangers that you met in the street. They have a power over your body and can do what they like. By the first day arrival, you don't know with whom you are, with whom you have sleeping quarter. Most of the time, group sex is common for the new comers. If you reject their idea, you might be beaten up and chased away from that particular place. Thus, the first day initiation into the street is the most difficult as to our experiences"(FGD). Fourteen-year interviewee said that he arrived at Addis Ababa around bus station at 6:00 PM. He was looking for shelter and something to eat and the time came to 8:00PM. He said, one of street boy told to have sleeping quarter with him. When he heard this, he was very happy. He gave me bread and took him to the railway building -where, he has been sleeping. He shared nigh cloth and sleeping quarter with the new comers and have it together. "Just after an hour, he forced me to have anal sex. I swear to St. merry, he had anal sex with me and continued it over the night. Starting form that day, I lost confidence to my sexual identity" (interviewee 7). Concurrently, seven interviewees shared the same experiences.

A female interviewee pointed that her mother was late and she is the only child for the family. Since the death of her mother, her father drank alcohol by every day. Later on, her father forced her to have sex with. At night always he drank alcohol and back to home and forcing his daughter to have sex.

"Hmmm...forcefully, he had sex with me for many times. This situation left me with its psychological pain. One day, I decided to escape from home to join street society. Then, I fled into the street. On her first day arrival of Addis Ababa street, she met one older street boy. He greeted and talked to her. He said, I think you seems new person to this area, she said yes. He requested for her to stay with, and she said, where? He told to her, "I am street boy and living here under railway building". "I said alright. But, now I am very hungry, would you give me something to eat? He run away and brought me bread. 
Then, I decided to be with him. We shared his night cloth and sleeping quarter, where we enjoyed sex over the night. With him I have been two years in the street as my informal husband. Sometimes, I am practicing prostitution and have a paid sex, to survive. Know, I felt the ideal freedom. Even though, I am selling my flesh to survive and facing many derogatory and abusive words in the street. Despite to this, I am psychologically free compared to with the previous time that I faced at home. Imagine, having sex with your father. Hmm....in my life, I don't forget its psychological pain forever" (interviewee 17). Similarly, two female interviewees reported the same tragedies (interviewees 19, 26).

Reportedly 5 of the 7, (71.5\%) discussants said by first day arrival to particular street, getting friends in the street seems a great opportunity. But, it has its own penalties. When you newly joined the street, you meet with the group of street society and they treat you with available basic needs. They gave you bread, night cloth and sleeping quarter, which is a great opportunity for you. But later on, you might be facing many hurdles. Over the night, they force you to have sex whether anal or vaginal. You know, first you treated well and later face the hideous life that you couldn't forget' (FGDs). Twentythree of the 26, (88.5\%) of interviewees pointed both male and female have the same sleeping quarters-which, promising for group sex. New arrivals used as sex object, by both older boys and shopkeepers'/ institution guardians. "Any sexual relations i.e., group sex, oral, anal and vaginal sex will happen to you-which, used as a defense for you. In the case of refusal for such sexual advances, you will be beaten up and chased away from that area" (interviewees). Male discussants (4 of the 7 FGDs) reported, to adapt with new society and survive, you should accept what your seniors said, whether it harmful or not. You should welcome whether sex, physical or verbal harassment. "The psychological trauma of post-anal penetration is the most painful that you cannot forget. You may think about it again and again. Even, you may face mental health problems like hopelessness, depressive symptoms, self-harm, and to the worst suicidal attempt. To be out of it, you may start drugs and get out of its pain. Gradually, adopt the pain of anal penetration and form harmonized relation with friends in the street. The situation is re-cycling. When you become senior, you may do the same thing to new comers and can't be out of this circuit" (FGDs).

Sub-theme 1.1: Pushing/pulling factors into the street life

Participants revealed the complexity of push and pull factors pose a risk of flee into the street. Pushing factors are any kind of influencing factors that force children to leave/escape from home and flee into the street. Five of the 7, (71.5\%) of discussants reported pushing factors such as poverty, separation of parents, family death, economic decline, single-parenthood, child abuse, neglect, school dropout, land grab and family eviction due to urban development and family size were the top causing factors of flee into the street (FGD). Following land grab, millions of local communities around capital city (Addis Ababa) have been forced to resettle without composition. In such essence, forced eviction of families fueled the number of street children in the country. Nineteen interviewees revealed that death of the family, destruction of extended relatives' relationship and schooling problem are the most common reasons of flee from home (interviewees). Pulling factors are those that draw/enticement children to flee into the street. Four of the 7 , (57\%) of discussants reported that "enticements of apparent freedom, financial independence, peer influence and traditional values i.e. adventure and city glamour were factors that draw children into the street" (FGDs). Due to the above factors, millions of children were fleeing into the street and being victim of its difficulties.

Sub-theme 1.2: Challenges of living in the street

Street children are facing many challenges and difficulties of street life. Discussants reported that when you face any of the pushing and/or pulling factors discussed above, you can't expect good situation to live with your family. The only chance is escaping into the street and enjoy the ideal of freedom. Interviewees noted, living in the street has many struggles, coercions, and maltreatments. "You might be facing many challenges in your street life-span. The only chance you have is, living with the sorest condition it" (interviewees). Reportedly, absence of clear and contextualized strategies and policies as-well-as little attention of government to address our difficulties made us highly vulnerable to any kind of problems and exacerbating (FGDs). They listed many problems, which are presented here below.

Category 1.2.1: Lack of social ties and networks

Five of the 7, (71.5\%) discussants reported starting from the day of flee into the street, they lost social ties and networks with their families and communities, where they live in. "We are considering ourselves as thrown-away children. We are living in ignored world by both our families and communities. We haven't any social ties and networks. We are the most deprived people, with no access to family love, care and affection. Nobody looks after you. You don't have anyone to share your idea with. For whom do you cry?" (FGDs).

Twenty- three of the $26,(88.5 \%)$ participants pointed street children are found instable-where they left family for abuse, community hate them for their dirty lifestyle and consider them as a crime person. Due to this, lack of proper social ties and networks with their family and community is common. "We are alone (no father or mother) who care for you. If you try to have healthy social networks with the community, the entire of the community hate you, due to our dirty living style, consider you as criminal and pin-pocket person", (interviewees). Six of the 7, (85.7\%) reported "Our social ties and networks are distorted. You feel hopelessness, your current and future life is shadowy. We cry out for help, but from where? There is no anyone in our side. At times we feel lonely; we suffer from lack of sleep, anxiety, isolation and mood depression. To hide yourself from such conditions, we use local alcohol, glue, hashish and Khat" (FGD).

Category 1.2.2: Critical shortage of coverage of basic needs

Page $7 / 16$ 
Three of the 7, (43\%) of discussants reported street children are young people who are living in ignored tragedy with the critical shortage of coverage of basic needs. Like other human being, they need basic needs from their biological families to have healthy life, but in their case, they are responsible to look for it. "At this age, we are conciliating our schooling and forced to engage ourselves in begging, collecting materials from the garbage, selling small things, manual work, prostitution and etc. You are the only one who act as a father or mother and responsible for daily coverage of basic needs. While looking for coverage of daily basic needs, we face many struggles and coercion from the street society and/or community (FGD). Twenty-three of the 26 , (88\%) of participants agreed the most challenge of living in the street is lack of coverage of basic needs. "The experience of street life appeared harder than the what the community think of it (interviewees).

Sub- theme 1.2.3: Physical, sexual and verbal harassments

Five of the 7, (71.5\%) of discussants reported street children are living in the world-where, they are forced for early sexual initiation, multiple sexual partners, group sex, either of homo or heterosexual. Most of them initiated early sexual intercourse before flee into the street-where, there is abusive families or extended families force them and be a main reason to be in the street. Others raped and forced to have sex either anal or vaginal in the street. These situation exposes them for health problems i.e. HIV/STIs, hepatitis, early pregnancy and its psychological trauma. "While living in the street, both male and female faces similar physical and sexual violence. Either of us have the fate of sexual harassment-which is the worst in the first day initiation into the street society-where you face the most intricacy of either anal or vaginal penetration. Anybody, either the street boy or shopkeepers/guardians do what they like. Both male and female will face this ugly life for advanced protection. You will stay in the same sleeping quarter (under railway building, veranda etc...), where you forced for unwilling practice. Such disinclined practices are rampant among us or outsiders.

Unprotected sex with strangers is common, where condom use is vested under the interest of strangers you met in the street. Most of male participants have reported post-anal penetration, psychological trauma is always memorable pain-which, you might be victim of it by the first day of joining with street society. When you become experienced, you can do the same thing to the new comers, if you don't afraid of your God" (FGDs).

Nineteen of the 26, (73\%) reported "You cannot out of harassments-where, any strangers do it, while you live in the street. Anybody can beat/slap you if you resist any unwilling practice. Sexual, physical and verbal violence are common and daily practice among street society and outsiders. We are living in ignored world, where there is no any social protection grantee you-which, exacerbate any type of harassments i.e. beating, slapping, sexual violence and even murdering" (Interviewees).

\section{Category 1.2.4: Child trafficking}

Even though the root causes for child trafficking is too difficult to know, millions of street children have been experiencing it, at least once in their life time. They are vulnerable to child trafficking, due to helpless implementation of social protection policy by the government. Five of the 7, (71.5\%), discussants reported child trafficking for cheap child labor and/or sexual intercourse. "We are highly vulnerable for trafficking. The trafficking encompasses within the city (Addis Ababa) or out of the city. People need you, for cheap uncompensated labor force and sexual activities - where you forced for cheap labor and/or sexual materialize (FGDs). Two of the 26 interviews reported street children have limited education and poor socioeconomic factors that made them vulnerable to trafficking. A fifteen-year boy interviewee reported "Me and my friend came from Harargeh (east part of the country). One day, two females came and have taken us to their home. After we arrived their home, they immediately offer us to shower and clothes to change. Then, they forced us to have sex. I have been there for three days and run away from. But, my friend is still there" (interviewees). Similarly, interviewees $(11 / 26)$ shared the same tragedies.

Theme 2: Means of survival and coping mechanisms

Street children as much as possible prefer and reside in areas with a special supportive environment and characteristics that do not conflict with their life-style, nor pose intimidations against their existence. They usually teach one another how to earn basic need coverage, where to go for living, and what to do in case they face problems, which is a clear exhibition of their sub-group culture. After flee into the street, they forced to have active role and participate in informal work sectors and survival sex to sustain their life. Discussants pointed "we survive through participating in transactional sex, scavenging garbage, labor-intensive work to change with bread, begging food from restaurant/hotels, take food from street food vendors, sometimes stealing, washing cars, selling small things like tissue paper and tooth brush, carrying luggage and heavy things (FGDs). Six of FGDs discussants reported their lives were full of struggles, coercions, and maltreatments, exploitation and violence among themselves and by shopkeepers, institution guardians, striders and hawkers in the street. Seventeen of the 26 interviewees reported living in the street environment places them at special struggles and coercions. To resist such actions, most of street children form small groups to counteract the negative influences and practices. They are extremely aware of the problematic and often dangerous environment in which they reside. They have obsessive concern about troubles and remind their group members to be lookout for situations that might lead to conflict. Hence, they tend to be strict in their practices, encouraging children to respect and 
participate in sub-group collective security. New comers are liable to have taken orientation and direction at the first time of joining the group. In such ways, they use different coping mechanisms to confront with the struggle of street life.

Sub-theme 2.1: Formation of group life and collective security

The journey of living in the street have full of struggles and coercions among themselves and outsiders. Many things are uncertain about how long they are living and die of violence. To cope up with such encounters, street children form a small group- where every member of the group has his/her role. The 6 of the 7 FGDs pointed to cope up with such a harsh lifestyle, they form a group-which, enable them mutual support and protection with a strong sense of companionship. They have their own group norm and culture with a code of street language.

Street children are governing interpersonal behavior and manage violence through, informal rules. The rules prescribe both a proper comportment and a proper way to respond if challenged. They regulate the use of violence and allow those who are inclined to aggression to precipitate violent encounters in an approved way. The rules have been established and are enforced mainly by well experienced street-oriented child. Everybody knows that if the rules are violated, there are penalties. "Street world is characterized by miserable deprivation, subjected to physical, verbal and sexual abuse, and victims of violence. We are forming a group and try to resist any violence in the form of group security. We have a group norm and culture, which leaded by one of brilliant street-oriented child. Through forming group security, we protect ourselves from any coercions. Within the group, there is sometimes intrapersonal violence, most likely by the older street children" (FGD).

Category 2.1.1: Inter or intra group conflict of interest

Discussants 5 of the 7 participants said most of the time, the group might be dysfunction and disperse its members. Many things are uncertain about how long we are living and we believe we may die due to violence among ourselves or by violent strangers at any time. They accept this fate and living in the border. Anybody can intimidate you; we try to counteract it. During this time, you don't know what will happen on you. "We discourage the violence as a primary solution of resolving disputes and encourage the group members to accept nonviolent behavior. But, if the negotiation goes down, every group member runs for self-defense. Many of us, much more concerned about the threat of our group norms. If somebody break the norm and culture, fighting within the group is common practice. Even though the nonviolent orientation rarely overcomes the impulse to strike back in an encounter, it may lead to certain confusion and lead to a profound violence among the group. Hence, the member of the group strives to go for bad action against each other (FGDs). Additionally, two female discussants reported females are mimicking the male behavior and try to have their own version of manhood. "When you act as manhood, you get respect and will be recognized by the group members. We try to achieve this in the ways that established by the boys and doing what the male street child do i.e. using abusive language, to be recognized person to actively participate in resolving disputes within the group or between the groups" (FGDs).

Five of the 7, discussants pointed conflict among street female exists due to the assessment of beauty girl within the group i.e. which girl in a group is the most beauty and competition over boyfriends within the group or from other groups. "A main cause of conflict within the group is he says, she says rumor. Usually one girl might be said something negative about somebody in a group, behind that person. The negative saying will back to the person talked about. In such essence, this might be led to group gossiping-which, it can be the main reason for the group violence and disperse" (FGD). Almost all of FGD discussants reported factors that increase risk of group violence behavior are a complex interaction or combination of factors leads to an increased risk of violent behavior. Factors like previous aggressive behavior, being victim, competition for the cute girl, drug use behavior and he/she said rumor about somebody are the most leading factors of violence within or between the groups. Due to this, the group will split over impossibility to keep violence and animosity between members at bay and look for another group to join.

Sub-theme 2.2: Sharing available resources and vital information

There is a compassion and caring culture among the sub-group of street children. The sympathy kindness and devotion of sub-group members of street children is astounding and astonishing. All of the $7,(100 \%)$ discussants noted everybody within the group has his/her mandate to look and search for daily basic needs. Some of the individuals participate in manual work, scavenging through garbage, begging, selling small things- whereas, female might be taking the responsibility to have survival sex and bring the money for the group. "Sharing resources and information is our fundamental activity. We have our own sub-culture which gave us group identity. The group has its own rule to welcome newcomers to the group with the mandate of orienting survival skills and socializing with the group. New arrivals oriented about means of survival and as streets are full of drugs and violence" (FGDs). The 17 of 26, (65\%) of interviewees pointed "to survive this harsh world, we are engaging ourselves in all kind of activities that bring money. At this age, we are engaging ourselves in shining of shoes, pushing trucks and gathering and carrying it to the dumpsite, sell rubber bags, tissue paper, tooth brush in the street, scavenging garbage and engaging in paid sex. To survive in the street, you engage yourself in any type of activities and ensure the group self-support." (Interviewees).

Page 9/16 
Six of the 7, (85.7\%) discussants pointed sharing vital information is the most important and imperative activity to survive. They move here and there to settle down in areas-where, they feel secure and gives them the possibility of earning for coverage of basic needs and able them to have fun with the group members. They prefer popular, market and commercial areas to be engaged in informal work sector-where, they earn living and enjoyment expense. Such areas are identified and informed via information sharing. "You know, there is interesting kind-heartedness and devotion among group members. You share important information to eam living and enjoyment expenses and bring it for the group members. You are responsible to bring money from any activities you get and share with your group members' (FGDs).

\section{Category 2.2.1 Sex as a means of survival}

Many research evidences show that street children are shift to prostitution as a means of survival. All discussants pointed most of street children turn to prostitution in order to survive. Both male and female are highly at risk of participating unwilling sex. Where, unprotected sex with strangers is common practice and made them vulnerable to health problems and early unwanted pregnancies. "To survive, we engage ourselves in prostitution. Prostitution is the main income generating activity for our informal wife. Over the night, if you see the streets, it is congregated with many young women. Most of them are our informal wife acting as prostitution ladies and seeking for paid sex. When she back to act as a wife, we share the money and expense for our basic needs. If she has informal husband within the group, her husband is the one who share the money with her. If the group lack coverage of daily basic needs, her husband is responsible to buy food for that particular day (FGDs).

Eleven of the $26,(42 \%)$ of participants reported if expense for survival is very tense, boys forced to have paid sex. Sometimes, boys engage themselves both in homo and heterosexual intercourse, due to immediate need of basic needs. "With outsiders' paid sex is common, if other means of survival are unsuccessful. Our intention is on the money rather than protected or unprotected sexual activities. But, if you have paid homosexual activity, its psychological pain was the most puzzling to categorize your sexual identity" (Interviewees).

Theme 3: Available government structures and street children perceived strategies to alleviate and prevent the occurrence of plights.

African governments are incapacitated and slow to address difficulties of the street children. Today, governments are increasingly taking ruthless and crooked steps to support and solve problems of street children. Such uncoordinated traditional response by most of African governments and elsewhere has been lagging to solve problems of street children. Even though there are policies and strategies targeting women and children, complete and representative data on the street children as-well-as strategies particular to street children are hardly available [3]. The Ethiopian government is not exceptional. The Ethiopian government, social protection minister developed social protection policy with the goals of protecting and promoting the wellbeing of its citizens under the country constitution and considering international and regional conventions. The policy stated that all Ethiopians have the right to social protection services including access to health care, education, shelter, good nutrition, protection, and reduce child labour. Also it stated vulnerable children have the right to access social protection services thru providing with school materials, food and shelter, IGAs. Moreover, the policy suggested strengthening community-based social support for vulnerable children-where the community are expected to support through buying school material, providing food and shelter [18].

Sub-theme 3.1: Governmental and non-governmental structure for child protection policies

Despite to the above mentioned Ethiopian policy, the government failed to implement the policy due to several factors i.e. designing problem of policies, strategies and programmes, budget allocation, poor inter-sectoral integration and lack of comprehensive standards were bottle neck of policy implementation. Furthermore, fewer and/or no political value for such victimized of young people is exacerbating the problems [12]. Consequently, street children have been considered as felon, out laws and having a mentality of committing crime by both law keeping bodies and society. This in turn, affecting this young people to be accepted by their community and get legal protection under the law-which, aggravate the problem against street children in Ethiopia.

The 6 of the 7, (85.7\%), discussants pointed, "We are human beings with no access to legal protection. We are forgotten groups by the government. The policemen always harass, beat and jail us without any evidence, because they don't think of us as a normal person with legal rights. Among us, if someone goes to prison with small crime or just with suspicion, it will be difficult to get him/her to bell out. No one cares or trusts us. We stay in prison for weeks or months, whether we do crime or not. We are just people with no legal protection services" (FGDs). Most of interviewees (19 of the 26, 73\%) reported "Government doesn't know us. Sometimes, we hear things over media about street children, but none of the government body have the intention of doing practical and reliable activities to respond to our problems. They just talk what they felt, but they don't know a bit about our challenges. They do not offer any viable alternative and failed to set down realistic and concrete solutions for our problems. On the other hand, policemen are our enemy. If something happens, we are their first option and victims of their ruthless beating. We are just bunch of criminals in their 
eyes; who happened to be out laws and just hate being legal. Hence, they beat us like dogs. How can we think that the government know us, while their people treat us like animals? It's ridiculous! Even animals have the right, but we.... Sometimes, the society is better. At least, we hustle and make our daily living, because they let us. There are good people who help and provide us with different things" (Interviewees).

Most 5 of the 7 , (71.5\%) of discussants reported absence of clear and contextualized strategies and policies as-well-as little attention of government to address and prevent our problems, made them more vulnerable to inhumanity practices. All FGDs reported the problem of street children is depending on individual situations and life experiences. In fact, their problem is sometimes individualized, depending on personal history that made him/her flee into the street and personal status at home and living in the street. "The care of street children must be effective through addressing personal situation by categorizing sub-group life experiences and holistically address the categorized problems. To do this, studying child profile and categorizing similar profiles and then, strategically attempting to solve is imperative for us. Therefore, better understanding of children living and growing up in the streets is essential" (FGDs). In such essence, key institutions or individuals understand the structural causes of street children situations and easily mitigate their problems case by case is imperious.

Sub-theme 3.2: Street children proposed and perceived strategies to alleviate and prevent the occurrence of plights.

This qualitative inquiry addressed street children's perceived strategies that support to develop clear, comprehensive and contextualized strategies to respond to difficulties of street life. This part of the study aimed to look at the street children's proposed strategies to discourse the plights against this young marginalised group and in need to attention. Their perceived strategies will benefit in recommending the Ethiopian policy makers and urban planners for urgent interventions. The participants listed the following strategies to be considered by the governmental and non-government organizations, communities and other interested stakeholders.

Category 3.2.1: Separate shelter to spend over the night

The Ethiopian social protection policy states ever vulnerable child is liable to have shelter, with very little and/or no implementation. Hence, absence of shelter imposing both male and female to have the same sleeping quarters. They are forced to share veranda, railway cove and open space etc. by group all together. Six of the 7, (85.7\%) discussants reported whatever the reason, being the street child is sleeping in insalubrious places, facing violence and becoming an expiatory victim of it. Street environment does not offer any social protection of shelter. Hence, they are victims of any type of harassments, cold and rain, since there is no safe sleeping quarter. The mainstreams of the street children are living in conditions of severe deprivation and unsafe environment-which place them at all kinds of risks. "We are living in harsh environment and with no shelter, where male and female share the same sleeping quarters. This situation amplifies sexual and physical violence among us and outsiders. If the government can hear us, we are loudly shouting out and looking for service of separate and safe night shelter" (FGDs).

Twenty-three of the $26,(88.5 \%)$ of interviewees pointed lack of night shelter in the street is providing an enabling environment for prostitutes-where, older street child, night guardians/watchmen forcibly engage them in unprotected sex. "We are begging for multi-cultural approach practices that might be amenable for the provision of night shelter. It benefits potentially to reduce the risk of harassments, cold and rain that we are suffering from" (interviewees).

Category 3.2.2: Access to regular health education, healthcare and life coaching services

Street children access to regular health education, healthcare and life coaching services are backbone to empower and address and prevent plights against them. Life coaching is a motivational and behavioural change approach that helps people to set and reach better goals, leading to enhanced well-being and personal ability of functioning [19]. Since, they are highly exposed to verbal, physical and sexual violence and psychosocial difficultieswhich, may be mitigated through assistance of caregivers (assigning volunteer ambassador mothers/fathers)- who have an interest and capacity to parent and support this young people by life coaching. Evidence shows that life coaching is a promising behaviour change approach for empowerment, efficiency and well-being of domestic violence survivals [20].

Nineteen of the 26, (73\%) of interviewees reported access to regular health, education, and life coaching services are essential to make street children healthy, educated and allow to a healthy and happy lifestyle. Due to absence of guidance and their lifestyle, the health of street children is strongly compromised form day to day. "We.... Street children do not have access to sanitary facilities that made us often dirty and infested with fleas. Due to lack of hygiene, we are exposed to different infectious diseases (Interviewees). Five of the 7, (71.5\%) of discussants pointed poor living styles have negative impact, not only on their physical and psychological development, but also their socio-economic development and social networks. "We are looking for any organizations or individuals, who make our education reality and who can help us to access health services and able to coach our living styles. If we are aware of the ways of infection transmissions, we recognize them and protect ourselves in the street life span. Not only this, such services are essential in increasing our socio-economic productivity as-well-as important in determining our future life" (FGDs).

Page $11 / 16$ 
Category 3.2.3: Effective implementation of child protection policy

The Ethiopian social protection policy implementation is highly important for this young people and should get in need of attention. Failing to provide special legal protection and social services for street children exposed them to child labour, trafficking, violence and moral problems that contribute in social and psychological predicaments. Twenty-two of the 26, (84.6\%) interviewees reported, since street children are marginalized group of young people, they are often victims of discrimination and facing inhumanity practices by day to day. "We do not have any human right protection services. implementation of such policy is vital for us. We don't know, if government consider us as a human being, we are in need of such practices"

(interviewees). Six of the 7, (85.7\%) of discussants highlighted, community members have prejudices and stigmatizing by naming and calling them as "street child". They pointed even the name "Godana tedadary" which means street child/children, is derogatory word that affect you morally. Not only this, the name itself support in community prejudices and spoil our social networking with the community-where, we are living. "Nobody stand behind us to look after or protect our rights. Anybody come and abuse you, whether physically or sexually. If it is possible, we are pleading for social protection that liable to ensure our safety and security. Generally, we are demanding government and/or non-government organization, for human right protection services. We are loudly shouting for basic human right protection. We are looking for any organizations or individuals who can ensure our right protection and possibly reduce our level of vulnerability that able us to live with a freedom" (FGDs).

\section{Category 3.2.4: IGAs for financial self-help}

Critical financial constraints forcing street children to participate in heavy manual activities, prostitution and child labor. Hence, financial burden is compromising their health, psychology and schooling. The Ethiopian social protection policy document stated that highly vulnerable children are liable to get IGAs training and provided with IGAs. However, street children responded and witnessed, as they never have seen such activities and practices [18]. All FGDs of study participants were highly interested to the IGAs for financial self-help. Discussants reported their working conditions are more hazardous and less likely to be protected by the employment legislation, since they are participating in informal sector activities. Twenty-four of the 26 , (92\%) of interviewees reported "We are looking for local authorities or international organizations support to establish micro-enterprise and able us for self-help, where the government ensure the safety of working environment with protected employment legislations. Every day, we are participating in informal sector activities-where the employer abuses you and even uncompensated payment. Sometimes, refuse to reimburse for the activities you have done". Six of the seven discussants reported; to ensure financial self-help, creating small micro-enterprises need to be gain attention and access to capital finance operations and training on the specified activities. Such generous support may relief our financial constraints and basic needs problems.

Sub-theme 3.2.5: Community strengthening as preventative strategy

One pillar of Ethiopian social protection policy states encouraging community-based social support for vulnerable children through buying school material, food and shelter. The community care coalitions, district level social protection committees allowed to collect voluntary contributions and allocate for vulnerable child social protection actions. Such informal mechanisms are important social support mechanisms that bedrock for child protection and empowerment. However, such practices are absent or rarely implemented in the community and contributing in the increment of street children in the cities and urbans. [18]

Almost all (24 of the $26,92 \%$ ) of interviewees preferred preventive strategies within the community in advance to prior flee. Preventive strategies within the community are a main concern and has importance to minimize the magnitude of street children in the street. They noted preventive strategies can address the main reason of flee from home before being a main reason. "For our most of street children, the main reasons of flee into the street are material and financial problems, abusive family like step mother or father, poverty and inability to schooling, land grab and family eviction are the factors lie behind the departure of us into the street (interviewees).

Six of the 7 FGDs said if the government body and community members detect their problems earlier and monitor through social welfare within the community, they might not be in the street today. Reported as they need social protection committee that funded and fully mainstreamed social welfare programmes in the community-where, they can early detect and take measurements against problems that lead into the street. "You know, if there are such services in the community for vulnerable children, it is possible to address the root cause and our complex challenges that made us the street boy or girl. Even, this can be addressed by the religious and community leaders-where they can do reality of our schooling materials, allow to enough food and advising our abusive families to not do" (FGD). Similarly, most (23 of the $26,88 \%)$ of interviewees are perceived preventive strategy as a main solution.

Fourteen-year old female interviewee reported "My father was late. After a year, my mother married another person. My step father made me always farming and denied my schooling. With this hard work, nobody cares about me. That is why, I joined the street society. Thus, if the community members responsibly, advocate the right of vulnerable child and mobilize the community for our rights and schooling materials as-well-as encouraging us to 
speak out for our problems, definitely they can prevent the suffer I am facing here in the street (interviewee 25). Most (21 of the 26, $81 \%$ ) of interviewees reported the same tragedy.

\section{Category 3.6.1: Reintegration with families or extended relatives}

Most research scholars support and recommend the value of reintegration into their families or extended relatives. However, most of study participants denied the value of reintegration strategy. Eighteen of $26,69 \%$ interviewees and (4 of the 7 FGDs) of discussants are denied the value of reintegration.

"Returning back to abusive families is not a good option. You fled into the street from where you have neglected, abused, denied schooling, farming, no enough food etc. and back to such families is unbearable. From such families you do not expect good things". Among the total participants only (8 of $26,31 \%$ ) (Male $n=5$ and female $n=3$ ) interviewees and ( 2 of the 7 ) focus group participants agreed positively the value of reintegration. Even though they have agreed on the reintegration, they highlighted that it should be with the legal background and the families should agree to nonviolent behavior and promise to schooling with the presence of witness. "Ideally, reintegration is a good solution. However, if your families do the same thing as previous reasons to flee, it hasn't sense. Due to this, during reintegration, our families should promise us nonviolence behavior and provision of schooling materials as well enough food". Even though most of researchers recommend the value of reintegration strategy, only few participants have agreed to it with outstanding preconditions-where, they beholding for forcing legal background to nonviolent behaviors of families and promising to schooling. This shows that the street children reason to flee into the street and life challenges in the street varies-which, needs identifying and categorizing problems and address through sub-culture and reason of flee and life experiences of street children.

\section{Discussion}

This study provided an occasion to gaze at initiation into street life, challenges, means of survival and perceived strategies to alleviate plights of street life in Addis Ababa, Ethiopia.

The study revealed that the complexity of push and pull factors that pose a risk of flee to the street. Of these factors participants reported poverty, divorce, separation of parents, death of one or both parents, economic decline, single-parent households, child abuse; neglect, alcohol abuse, school dropout, family size are among pushing factors. Enticements of apparent freedom, financial independence, friendships and traditional values i.e. adventure and city glamour are among the pulling factors that draw children into the street. Similarly, the study conducted in Ethiopia and Sudan shows that prior hardships i.e. death of family, war, destruction of extended relative relationship, denied to basic needs, sexual and physical harassments are imminent factors influencing children into street life [14, 21].

The report of global child protection services shows that difference and diversity are poorly tolerated and leading to neglect and abandonment of children in many cultures. Existing social norms and cultural attitudes towards children often allow abuses of children's right to care and protection. Furthermore, conflict, disasters, food insecurity do to climate change, social exclusion, violence, lack of access to education, exploitative and hazardous child work, migration and urbanization are major predisposing factors to initiation of street life [3].

It revealed that both of first day's exposure to street life and throughout the span of street life has its own challenges. They are facing the challenges of critical lack of basic needs, shelter and any type of harassments i.e. verbal, physical or sexual abuse. Sexual relations i.e. group sex, oral, anal and vaginal sex are common harassments among street children or with the community. Mostly, such sexual relationships are used as a defense for the new comers and means of survivals. In the case of refusal of such sexual advances, the new comers are beaten up and chased away from that area. This study finding is consistent with the study conducted in Malawi and Ethiopia $[4,14]$. This finding shows that social network fragmentations from biological families and communities and critical shortage of daily basic needs, sexual harassment where both male and female faces similar sexual violence and child trafficking are identified as the main challenges of street children. In line to this finding, the study conducted in Kenya and Ethiopia shows street children are facing similar tragedies [14, 22].

This study revealed, street children are living in the world where they are facing day to day sexual, verbal and physical harassments. Due to this, they are forced for early sexual initiation, multiple sexual partners, group sex i.e. homo or heterosexual that leads to early pregnancy, health problems and psychological trauma. Particularly, new arrivals are prone to sexual abuse and exploitation by older street boys, group of street children or watchmen to secure their protection in advance. Thus, both male and female street children are highly at risk of sexual violence. Concurrently, the study conducted in Ethiopia shows that about $27.5 \%$ of street children practiced sexual intercourse in their life time, of which $44.6 \%$ had begun sexual intercourse before the age of fifteen and $75 \%$ have had multiple sexual partners [11].

This study shows that both forced and unprotected sexes were common among street children due to low negotiation capacity of condom use and influences from sexual partners. Willingness for rampant sexual activities serves them as a main source of income to quench their immediate need of food and shelter; their intention is just getting money than worrying for protected or unprotected sex. Similar study conducted in Ethiopia shows that about $32.3 \%$ were raped forcefully, $49.7 \%$ had conducted survival sex, while $14 \%$ of street children had used condom [11, 15]. 
This study revealed that street child trafficking is a prominent challenge that occurs either within or out of city for uncompensated child labor or sex. Limited education or illiteracy and poor socio-cultural background are major factors for vulnerability of child trafficking. Report from street children indicates that house detention and enforced sex with strangers or free exploitation of labor are usually their fate after trafficking. Concomitantly, the report of international programmes on the elimination of child labor shows that in Kathmandu, ambitious lies and fake promises to either the children or their parents are ways of wining their heart for trafficking. As a result, at least fourteen street children were forced to child trafficking for the purpose of domestic child labor, where their working conditions at the first distention was unsafe both psychologically and physically. The majority of them did not get enough food or decent place to sleep and paid uncompensated payment [23].

The finding shows that street children organize in small groups in order to endure the hostility of street life through socialization, sharing vital information and resources for survival- where every individual within the group has his or her mandate. Sharing tasks within a group is mandatory where some participate in manual work, scavenging through garbage as well as begging. Whereas, females might be taking the responsibility of having commercial sex and give that money to the group because sharing resources and information is fundamental in their subculture. Alongside of this finding, the study conducted in Tanzania shows that street children have high sexual risk taking intentions to survive [24]. Additionally, study from Bangladesh shows that the survival means of street children found to be quite atypical- where they would involve in unpaid manual, non-domestic works in different marginal occupations (e.g. begging, street vending, remnants and edibles picking from dustbins, prostitution, selling flowers on the roads to the passerby etc.). They live their life with daily earned money, food from street food vendors by stealing or begging from hotels or restaurants $[13,8]$.

This study shows that street children perceived positively the value of separate shelter, creating income generating activities, regular health education and life coaching, controlling body for safety and right and prevention strategies within the community are perceived strategies to solve the street children challenges. Similarly, Ethiopian policy stated vulnerable children has the right to social services including basic human rights, health care, education and good nutrition, community-based social support, provision with IGAs training and involving them in IGAs and other studies recommend similar strategies to alleviate the challenges of street children $[15,18,22,25]$. Whereas, this finding revealed that some of study participants were denied the value of reintegration strategy. In contrary of this, dozens of researchers are recommended the reintegration strategy as a possible solution [11, 26, 27].

\section{Conclusion}

The study has explored the street children experiences of initiation into the street, challenges, and means of survival as well as perceived strategies to alleviate the street life difficulties. Participants revealed the complexity of push and pull factors pretense the risk of flee into the street. They are facing challenges of social networking fragmentations, child trafficking, sexual and physical harassments and critical shortage of daily basic needs. As a means of survival, street children are using available opportunities through forming small groups- where, every individual within each group has his/her mandate for collective security, sharing available resources and vital information that might be useful. Factors i.e. previous aggressive behavior, being victim of physical or sexual, competition of getting the cute girl and drug use behaviors are the main cause of conflict within or among groups. The local and national government gave little attention to address the plight of street children. Little attention and lack of strategies targeting street children has made them prone to health problems. Furthermore, stigma by the community, limited resources, lack comprehensive standards and absence of political value of interventions exacerbating the problems.

\section{Recommendations}

Therefore, call for different stakeholders in supporting to design and implement clear, case based and contextualized strategic policies to address and prevent plights; by considering positively perceived street children's proposed strategies, i.e. IGA, shelter, supporting vulnerable child, child protection, regular health education, access to health services and life coaching should have to be considered. Addressing the plight of marginalised group of young people in need of attention and urgent interventions to improve their right, health and wellbeing should be considered. Risk reduction programmes targeting street children by multi-cultural perspectives and involving government, nongovernment organizations, community members and parent engagements should have to considered.

Limitation of the study: This study employed only street children-where organizations or guardians who are working with this marginalized people were not considered.

\section{Abbreviations}

ETB: Ethiopian Birr, EPHI: Ethiopian Public Health Institute, FGD: Focus Group Discussion, IGA: Income Generating Activities, LMICs: Low and Middle Income Countries, NGO: Non-Governmental Organization, OVC: Orphan and Vulnerable Children, TSS: Time-Space Sampling, 


\section{Declarations}

\section{Ethics approval and consent to participate}

Ethical clearance was received from Ethiopian Public Health Institute. A formal letter was written to all concerned authorities and permission was secured at all levels. Since the study participants were younger, written assent was taken from study subjects and consent was taken from guardians or non-governmental organizations (NGOs) that are working with. To compensate participants' time, the researchers provided 50 ETB (1.9 USD) per person.

Consent for publication: Not applicable

Availability of data and material: Up on the request, data and material is available

Competing interests: The author declare that he has no any competing interests

Funding: This research has not been funded from any sources of organization.

Authors' contribution: ACF conducted this research from the inception to manuscript write up, alone.

Acknowledgments: The author would like to heartfelt thanks of the study participants who devoted their time to participate and contribute for the success of to this study.

\section{Publishers note: Let's Stand Together to Bloom Hope of Worldwide Street Children!}

Author detail: Fite, Ayana Chimdessa (B.Sc., M.Sc. and MPH in RH), College of Medicine and Health Sciences, Ambo University, Ambo Ethiopia.

\section{References}

1. Mehdi Ali (Dr.) Regional Representative for the Middle East and North Africa, Rapid situation assessment of street children in Cairo and Alexandria report

2. Patricia Ray, Corinne Davey and Paul Nolan Analysis of policy and programmes related to street involved children

3. Samuel N. Cumber and Joyce M. et, al. (2015) The health profile of street children in Africa: a literature review, Journal of Public Health in Africa; 6:566.

4. P Mandalazi, C Banda, E Umar (2013) Street children's vulnerability to HIV and sexually transmitted infections in Malawian cities Malawi Medical Journal (25)-1

5. Demelash H. and Addisie A. (2013), Assessment of Sexual and Reproductive Health Status of Street Children in Addis Ababa, Journal of Sexually Transmitted Diseases:2013:524076.

6. Laura K. Murray, Namrita S. Singh: (2012|) A Qualitative Study of Georgian Youth Who Are on the Street or Institutionalized Int J Pediatr. Article ID 921604.

7. Jessica w. et.al 2013 the health status of street children and youth in low-and middle-income coutries; systematic review of the literature, journal of adolescent health and medicine https;//dx.doi.org/10.1016/j.jadohealth

8. Jessica Woan, M.D. a, Jessica Lin, et.al, The Health Status of Street Children and Youth in Low- and Middle- Income Countries: A Systematic Review of the Literature Journal of Adolescent Health 53 (2013) 314e321.

9. Aurelie Tinland, Laurent Boyer 2018

10. Tengeru institute of community development (TICD), 2016

11. Fite A.C and Cherie, A. (2016) Risky Sexual Behavior and Its Determinants among Orphan and Vulnerable Children in Ethiopia, World Journal of AIDS, 6, 111-122

12. Nahom Eyasu, 2018 Policy Briefing on Child Protection Policy of Ethiopia in Emergencies Vol. 18 Issue 3 Version 1, Global Journal of HUMANSOCIAL SCIENCE: Online ISSN: 2249-460x \& Print ISSN: 0975-587X, Sociology \& Culture]

13. Abdul Hai et, (2014) all Problems Faced by The Street Children: A Study on Some Selected Places in Dhaka City, Bangladesh International journal of scientific \& technology research volume 3 , issue 10 ,

14. Chimdessa and Cheire BMC Pediatrics (2018): Sexual and physical abuse and its determinants among street children: Qualitative study in Ethiopia BMC Pediatrics 18:304

15. Chimdessa, A., Olayemi, O. and Akpa, O.M. (2017) Factors Associated with Vulnerability to HIV and Sexually Transmitted Infections among Street Children in Selected Towns of Ethiopia. World Journal of AIDS, 7, 230-238

16. Nagash W., terefe W., et,al. 2020, bmc public health Sexually transmitted diseases among street children dwellers in southern Ethiopia https;//doi.org/10.1186/s12889-020-08584-x

17. Paper to be presented to an International Conference on Street Children and Street Children's Health in East Africa, to be held in Dar-es-Salaam, Tanzania, April 19th - 21st April 2000). 
18. Ethiopia [NATIONAL SOCIAL PROTECTION POLICY OF ETHIOPIA, 26 March, 2012]

19. J., 2016 what is life coaching? an integrative review of the evidence-based literature inter. Journal of evidence based coaching and mentoring, 14(1), 34-56

20. B., kath w., et.al 2019 journal of family violence assessing the feasibility of a parent life coaching intervention to support parents and children who have experienced domestic violence and abuse

21. Mary L. P, Mustafa Kudrati and Nassrin D. (2007) Beginning Street life: factors contributing to children working and living on the streets of Khartoum, Sudan 29(12): 1520-1536

22. .Juma M, Jane Alaii LKB, lan Askew,and Bart Van den Born: (2013) Understanding orphan and non-orphan adolescents' sexual risks in the context of poverty: a qualitative study in Nyanza Province, Kenya,. Jumaet al BMC International Health and Human Rights.

23. International Programme on the Elimination of Child Labour, (2002) Trafficking and Sexual Abuse among Street Children in Kathmandu, no 1; IPEC: Trafficking in Children-South Asia (TICSA), First Published

24. Boston University Center for Global Health, Nigeria August 2009. Effect of Economic Assets on Sexual Risk- Taking Intentions Among Orphaned Adolescents in Uganda.

25. Amuyunzu-Nyamongo MB, AE.; Ouedraogo, C.; Woog, V. New York: The Alan Guttmacher Institute; (2005) Qualitative Evidence on Adolescents' Views of Sexual and Reproductive Health in Sub-Saharan Africa Occasional Report.

26. Ljungqvist B. Millennium dream campaign, UNICEF Representative in Ethiopia 2007.

27. L. Holley, A.C. Wilson, M. Noel, and T.M. Palermo (2016), Post-traumatic stress symptoms in children and adolescents with chronic pain: A topical review of the literature and a proposed framework for future research, Eur J Pain. 20(9): 1371-1383. doi:10.1002/ejp.879. 